\title{
Práticas de estarcom como gesto de cuidado e criação
}

\author{
Practices of beingwith as a gesture of care and creation
}

\begin{abstract}
Lidia Costa Laranjeira; Ruth Silva Torralba Ribeiro
\end{abstract}
Universidade Federal do Rio de Janeiro

\section{RESUMO:}

O presente texto apresenta e discute ações de ocupação corpo-cidade, desenvolvidas no Rio de Janeiro entre 2015 e 2018, pelas integrantes e colaboradoras do Núcleo de Pesquisa, Estudos e Encontros em Dança - onucleo - DAC/UFRJ. Denominamos as referidas ações de práticas de estarcom, evidenciando a dimensão cartográfica, afetiva e conectiva do encontro entre corpo e território. As práticas de estarcom são fazeres de dança que não visam a exibição de movimentos coreográficos, mas atentam-se ao gesto, aos pré-movimentos, ao campo de forças e à abertura para a dimensão somática da presença. O estarcom configura-se como um gesto de cuidado coletivo e horizontal pensado a partir de perspectivas decoloniais ligadas a aproximação com a cosmovisão dos povos originários. Através das práticas de estarcom afirmamos o cuidado como ação coletiva que possibilita a partilha de experiências da ordem da alegria, do bem viver e da convivência com a diferença.

Palavras-chave: encontro;cuidado; ocupação corpo-cidade.

\section{ABSTRACT:}

This paper presents and discusses some occupation actions, developed between 2015/2018 in Rio de Janeiro, by members and collaborators of Nucleo de Pesquisa, Estudos e Encontros em Dança - onucleo - DAC/UFRJ. Named as practices of beingwith the actions developed evoce the cartographic, affective and connective of the encounter between the body and territory. The practices of beingwith are located as a dance subject that do not aim at the exhibition of choreographic movements, but focus in the gesture, the pre-movements, the force field and the opening to the somatic of the presence. Beingwith is a gesture of collective and horizontal care thought out from decolonial perspectives linked to the approach to the cosmovision of the original people. Through the practices of beingwith we affirm care as a collective action that makes it possible to share experiences of the order of joy, good living and living with difference.

Key-words: encounter; care; ocuppation.

DOI: 10.12957/mnemosine.2020.57655

\section{Prólogo}

A escrita deste texto, e de todos os textos de nossa época, foi pega de surpresa pela pandemia do COVID-19 ${ }^{1}$. Estamos, agora enquanto escrevemos, completando um mês de 
confinamento em isolamento social. Em larga escala, isto significa uma multiplicidade de desdobramentos imprevisíveis, e em nossa micro escala, significa que nos foi retirada a possibilidade de realizar a matéria do trabalho que aqui viemos discutir: o encontro... elemento fundante das práticas de estarcom. Então, como começar? Como parir um texto se não somos mais capazes de imaginar que tipo de mundo vai recebê-lo? Como escrever se nossa memória prospectiva, se nossa capacidade de nos imaginarmos no mundo porvir está em colapsado? E, superando esta paralisante desorientação espaço-temporal, como repensar um cuidado horizontal a partir de práticas de estarcom quando, justamente, o problema que ameaça as nossas vidas e o mundo tal como o conhecemos está pedindo que redescubramos o encontro entre nós, o encontro em nós?

Davi Kopenawa, xamã yanomami, abre seu celebrado livro escrito com Bruce Albert, A queda do céu, com a visão de um futuro que, ao que tudo indica, nos aguarda se nada for feito "para que o céu não caia":

A floresta está viva. Só vai morrer se os brancos insistirem em destruí-la. Se conseguirem, os rios vão desaparecer debaixo da terra, o chão vai se desfazer, as árvores vão murchar e as pedras vão rachar no calor. A terra ressecada ficará vazia e silenciosa. Os espíritos xapiri, que descem das montanhas para brincar na floresta em seus espelhos, fugirão para muito longe. Seus pais, os xamãs, não poderão mais chama-los e fazê-los dançar para nos proteger. Não serão capazes de espantar as fumaças de epidemia que nos devoram. Não conseguirão mais conter os seres maléficos, que transformarão a floresta num caos. Então morreremos, um atrás do outro, tanto os brancos quanto nós. Todos os xamãs vão acabar morrendo. Quando não houver mais nenhum deles vivo para sustentar o céu, ele vai desabar. (KOPENAWA, 2015: 60)

É urgente segurarmos o céu, adiarmos o fim do mundo, “inventarmos novos modos de estar junto, de fazer conexões, de engendrar economias afetivas (...) de nos abrirmos a processos de cocriação e coexistência, onde seja uma entre-humanidade nunca antes vista a que se afirme e resista (...)",

\section{\{Convidamos}

você a fechar os olhos. Pousar as pálpebras, repousar o globo ocular em suas órbitas e observar o apoio dos pés no chão. Olhar para dentro. Escutar o espaço. Ouvir os micromovimentos da pulsação da vida no 
corpo. Inventariar os espaços de prazer e neles re-pousar pelo tempo necessário...\}

\section{Uma flecha de um mundo passado não tão distante}

As práticas discutidas neste texto foram selecionadas de um conjunto de experimentações realizadas dentro do projeto "Cartografias do Corpo na Cidade", desenvolvido de 2015 até 2018, pelo Núcleo de Pesquisa, Estudos e Encontros em Dança - onucleo constituído de um ajuntamento de mulheres - pesquisadoras, artistas, professoras e estudantes de dança - relacionadas aos cursos de graduação e pós-graduação em Dança do Departamento de Arte Corporal da UFRJ. Coordenado institucionalmente por nós e gerido coletivamente desde o princípio, a horizontalidade das relações construídas pel'onucleo, através de iniciativas coletivas e de reflexões partilhadas, merece consideração especial por revelar que tudo o que descrevemos nessas práticas tem a carne de todas e de cada uma de nós. Escrevemos na primeira pessoa do plural incluindo as presenças de Thais Chilinque, Bruna Gouvea, Laura Vainer, Raquel Oliveira, Tamara Rothstein e Bruna Belem. E também das colaboradoras Mariana Lemos, Nina La Croix, Aline Bernardi e Thaina Farias.

A pesquisa adere, desde o princípio, uma determinada política do encontro que fricciona os limites entre arte-e-vida, criando composições coconstitutivas entre corpo, movimento, gesto, cidade, escrita, imagem, som e processos de subjetivação. Uma determinada política do encontro pautada em relações de sintonia, afeto e ressonância. Política pautada também na crítica à lógica de poder colonial - de comando e obediência - que embasa os processos de formação e criação em dança denominados atualmente de coreografia. Pensamos nosso trabalho em termos de uma dança expandida contracoreográfica ${ }^{4}$, que questiona e re-localiza a tradicional doxa da dança através da produção de percepções, reflexões e fazeres. Esses fazeres, que denominamos de práticas de estarcom, giram em torno de ocupações coletivas, somáticas e artístico-afetivas de espaços específicos da cidade. As práticas de estarcom tornaram-se, além de experiência significativa de cuidado e transformação pessoal, objeto de escritas cartográficas, trabalhos acadêmicos, produções artísticas e reflexões como as que aqui desenvolvemos.

Discutiremos, a seguir, algumas linhas de força de investigação teórico-práticas que reconhecemos em nosso trabalho para criar, nessa escrita, um plano de composição ou de consistência que identificamos como zonas intensivas em nossa pesquisa. 


\section{Práticas de estarcom para inventariar novos mundos}

As práticas de estarcom são dispositivos de criação de um campo comum de ressonância para experimentações das corporeidades na cidade, criadas como fabulação, fabricação, invenção de hipóteses para as perguntas que nos assombravam naquele momento do trabalho: Como dançar em tempos em que o chão está em plena erosão? Como dançar depois dos “sismos” políticos de junho de 2013, do golpe de 2016 e das eleições presidenciais de 2018 ? Como manter-nos conectadas com movimentos que ativam a dimensão vibrátil dos corpos e acionem possibilidades de re-existência na cidade e em seus diferentes territórios? Como permanecer dançando e produzindo movimento de vida em tempos que se mostram ameaçadores para as existências não hegemônicas? Como seguir produzindo uma dança em ressonância com as potências alegres e ativas do mundo? E que mundo criamos com nossas políticas do encontro e seus modos de estarcom, de agir e de inscrever presença?

As práticas de estarcom são pensadas como fazeres de dança não por encadearem sequências de movimento coreográficos, mas por atentarem ao gesto, ou seja, aos prémovimentos em todas as suas dimensões afetivas e projetivas ${ }^{5}$ bem como ao campo de forças e à abertura para a dimensão somática da presença. Nessas práticas inauguram-se novas potências de relação, corporeidades e possibilidades de criação. O cuidado que emerge nessa relação move-se no contra-fluxo do controle e da obediência posto que opera num espaço relacional, numa aposta sem garantias que tem o chão da Terra como suporte-colo.

As relações entre os corpos e os espaços da cidade não estão completamente dados em suas práticas ordinárias. A qualidade da presença e a atenção criam e modificam a maneira como nos relacionamos com as pessoas e os lugares. Nas práticas de estarcom, percebemos que ocupar, insistir, resistir e inventar os espaços públicos pode forçar novas possibilidades de convivência, ressignificando os afetos, ajudando a reimaginar o sistema de representação macro e micro político, sendo assim possível reinventar e reimaginar o chão que erode sob nossos pés.

\{Convidamos você a atentar para as sensações que a geografia do espaço em que você se encontra produz: observe detalhes não ordinários do seu entorno, oriente-se a partir das costas, escolha posições não habituais, saia do tempo cronológico, perca-se por alguns momentos.\} 
Em termos práticos, combinávamos previamente o horário, a duração e o lugar da cidade em que nos interessava estarcom (região portuária, Morro da Conceição, Praça Duque Costa, Aldeia Maracanã, OcupaMinc, OcupaSus, OcupaAmaro, Praça da Cinelândia). Reuníamos-nos em nossa chegada ao território e experimentávamos a abertura para um encontro em que a escuta e a dilatação da atenção eram guia. Era necessário criar um distanciamento dos assuntos e problemas ordinários, instaurar um silêncio, uma lentidão e, assim, abrir a dimensão somática dos nossos corpos para adentrarmos em percepções de mapeio - geográficas e cartográficas não usuais na nossa relação com os espaços da cidade. 1) Carregamos e montamos uma cama vó da Thais no mirante do Cais do Valongo. A gente deitou e olhou a vista enquanto uma chuva torrencial caiu. 2) Caminhamos, paramos, conversamos, comemos pelas ruas do Morro da Conceição enquanto a Laura sentia o chão pela sola de sua sapatilha de balé. 3) Arrastamos um carrinho de feira que deixava como rastro um caminho de pétalas de rosa. 4) Levamos pratos com água para a Pedra do Sal e ficamos a olhar o céu pelo reflexo 5) Experimentamos ações paradoxais entre nós, como agarrar-largar, dar-receber, tecer-destecer em diferentes lugares da cidade. 6) Sintonizamos escritas intergalácticas no mesmo horário com pessoas em diferentes lugares do mundo: Lisboa, Madri, São Paulo) 7) Fizemos leituras, piqueniques e conversas nas sombras das árvores. 8) Limpamos o chão do Colégio Amaro Cavalcanti com os estudantes ocupantes da OcupaAmaro 9)Visitamos a Aldeia Maracanã ${ }^{6}$ 10) Fizemos danças para os moradores nas janelas 11) Tomamos café da manhã com os vizinhos da Praça da Jogo da Bola. 12) Lemos um texto sentadas na calçada da Fortaleza do Morro de Conceição. 13) Tomamos chá de erva cidreira colhido no muro de uma das ruas do Morro. ${ }^{7}$

As práticas de estarcom convidam à instauração de uma dança contracoreográfica descomprometida com a exibição de algo: sem cena, sem público, sem ensaio e sem repetição. Uma dança comprometida com o micro e com o pré-movimento, com uma escuta ressonante que procura e deseja encontrar aquilo que viemos chamando de OUTRO. Estarcom o OUTRO - pessoas e lugares - como convite à renovação do sentido da vida, à abertura de brechas para que as potências alegres e ativas possam emergir... Estarcom como reinvenção das forças de ação...

\section{Cuidado como prática coletiva}

Nosso tempo é especialista em criar ausências: do sentido de viver em sociedade, do próprio sentido de experiência da vida. Isso gera uma intolerância muito grande com relação a quem ainda é capaz de experimentar o prazer de estar vivo, de dançar, de cantar. E está cheio de pequenas constelações de gente espalhada pelo mundo que dança, canta, faz 
chover. O tipo de humanidade zumbi que estamos sendo convocados a integrar não tolera tanto prazer, tanta fruição de vida. Então, pregam o fim do mundo como uma possibilidade de fazer a gente desistir dos nossos próprios sonhos. E a minha provocação sobre adiar o fim do mundo é exatamente sempre poder contar uma história. Se pudermos fazer isso, estaremos adiando o fim. (KRENAK, 2019: 26-27)

Estarcom como prática de cuidado nos impele a pensar o cuidado para fora do sentido tradicional das práticas psi que operam através de uma experiência interpessoal e do ato de rememoração e de reatualização do sofrimento do trauma. Distanciamo-nos também da perspectiva médico-científico que se instrumentaliza através de um saber vertical que se configura numa relação especializada de saber-poder e numa lógica dual de saúde/doença.

Afirmamos o cuidado como prática coletiva e transpessoal que viabiliza a partilha de experiências da ordem da alegria, da festa, do prazer, da satisfação, do bem viver, da convivência com a diferença. Essas experiências instauram um sentido restaurativo da saúde e da vida. O cuidado de que trataremos aqui está fora da lógica de passividade/atividade e se configura como experiência coletiva e horizontal partilhada através de práticas comuns que têm o afeto como fio conectivo. As práticas de estacom acima descritas se sustentam nesse fio de cuidar. A experiência de cuidado é assim um ato político que quebra com o sentido de individualidade difundido na modernidade e tão operante na contemporaneidade.

O modo como experimentamos a subjetividade na dança que realizamos através das práticas de estarcom dimensionam a vida num plano comum, de indissociabilidade corponatura que está muito próxima ao modo de compreensão da existência dos povos originários de nosso território. Como nos conta Ailton Krenak (2019), o antropoceno ${ }^{8}$ nos distancia da realidade, nos impondo a abstração da unidade e do homem como centro do Universo, negando a heterogeneidade que nos constitui e a co-dependência dos seres necessária à expansão da vida. Contra o vírus antropocêntrico, Krenak nos desafia a criar paraquedas para viver o fim do mundo e abrir espaços no solo duro do concreto para poder sonhar, quebrando assim o "casulo" do humano individual, racional e consciente para experimentar outros modos de vida, outras cosmovisões menos limitadas em relação o projeto de homem antropocêntrico.

Nesse sentido, o cuidado que experimentamos estaria mais próximo da experiência do xamã do que da expertise do médico. Não nos interessa cuidar somente do corpo, mas também do chão, do nosso território. Se o antropoceno instaurou uma enorme ferida em Gaia, precisamos, para cuidar de nós, cuidar da Terra, da cidade, do coletivo. O cuidado do corpo 
individual e da psique individual não basta nesse mundo que sonhamos e que plantamos como nossas práticas de estarcom.

Kaká Werá (2016) nos conta que o xamanismo tupi-guarani pressupõe uma investigação de si, sendo assim um caminho de autoconhecimento que só pode ser exercitado por uma profunda devoção à vida. Essa experiência se expressa por uma dupla atitude: uma interior de gratidão e outra exterior de cuidado com o tekoá, que é "o lugar onde vivemos". O lugar onde vivemos não se separa do corpo que habitamos.

Na cosmovisão tupi-guarani, o ser é som, expressão da vibração da Terra. Segundo Werá, a palavra tupy significa "som assentado" e advém de Tu (trovão) e Py (corpo físico). Essa vibração primordial do corpo físico da Terra $(T u)$ assenta em nós em nossos corpos $(P y)$, gerando vida. Tupy também advém de Tupã que significa "fonte divina" ou "grande espírito", o que indica que no pensamento tupi-guarani cada um de nós guarda em si o sopro do mundo.

A palavra ser, $a y v u$, significa vento e esse vento que somos se expressa também como trovão, como som que vibra a terra. O ser é assim parte da fonte de vida e quando expandimos o campo vibratório de nossos seres, com cuidado e atenção, todo o corpo vibracional do mundo pode fluir.

Tupã é também Nhamandu, aquele que é tecido do vazio e do silêncio. Vazio e silêncio que demonstram como a vida é sempre movimento e criação incessante, fonte inesgotável de energia. Através do vazio e do silêncio podemos experimentar oguerojera, "o desdobramento da fonte em seu eterno desabrochar", em seu fluxo, em seu movimento e assim nos sentimos como parte desse grande sopro infinito. Nesse ponto, experimentamos um estado de presença e de conexão corpo-mundo.

A sabedoria guarani diz que, embora cada indivíduo tenha seu Nhanderu (ou se já, seu jeito particular de ser, de se manifestar na existência material), em essência as mesmas forças e energias nos sustentam (...). Por isso, essa ética profunda resulta em uma segunda consideração: por meio da inclusão e do respeito, é natural e espontâneo honrar todas as nossas relações, pois elas se revelam como extensões de nós mesmos. (WERÁ, 2016: 58)

O xamã experimenta um corpo atravessado pela vida, por outros corpos e por outros espaços-tempos. O ser é extensão da relação com o outro. Longe de tentar aqui nos identificar com essa figura de poder que é o xamã na cosmovisão tupi-guarani, trazemos o xamã como uma imagem, um sonho, uma perspectiva para evidenciar o plano coletivo da experiência de cuidar que não se diferencia da experiência de ser corpo com o mundo. Apostamos numa experiência de cuidado que se faz através de dinâmicas co-espaciais, atmosféricas, vibratórias, 
intensivas e coletivas que descolonizam a tradicional noção individual de cuidado fundada na lógica antropocêntrica.

\section{Teko haw ${ }^{9}$ : o lugar onde vivemos.}

Rio, 13 de novembro de 2017: encontro com a Aldeia Marakan'à ${ }^{10}$

O chegar já é um desarrumar dos caminhos assegurados.

Marcamos e não deixamos um ponto de encontro.

O corpo fareja e acha. Segue e se encontra.

Pegamos o metrô (Lídia, Aline, Raquel e eu) e desaguamos no Maracanã... Aguardamos

Thaís.

Ela chega e seguimos.

Azul no céu que se abre luminoso sobre nossas cabeças.

Horizonte sinuoso de montanhas: de um lado a Floresta da Tijuca e do outro o Morro da

Mangueira.

Aline pede pouso e sombra para ajustar o modo de como chegar, encontrar.

Seguimos e daquele ponto o corpo se alarga, não há tensão, só escuta, presença, desejo de encontro.

A paisagem do lado de lá da cerca chama, convida a olhar e a estar. 


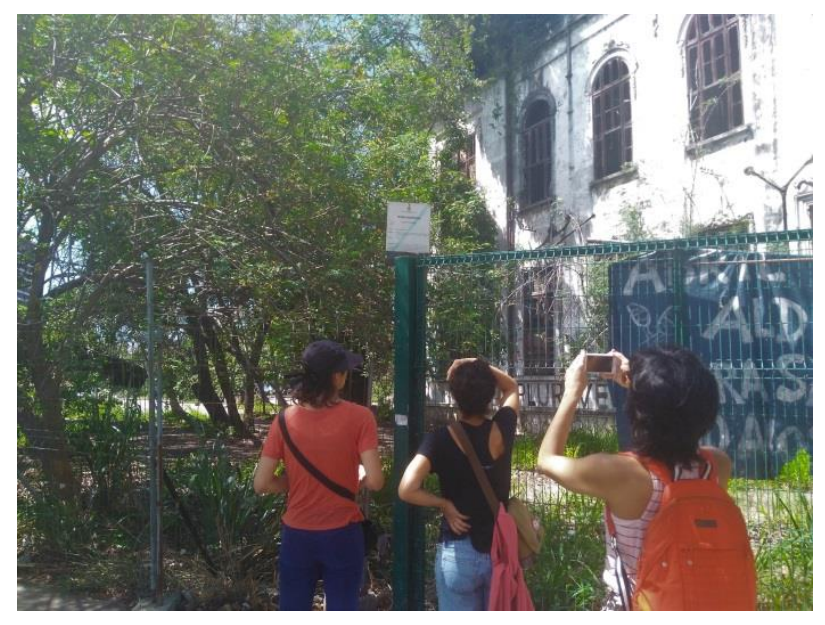

Cartografia onucleo - Aldeia Maracanã - Chegada

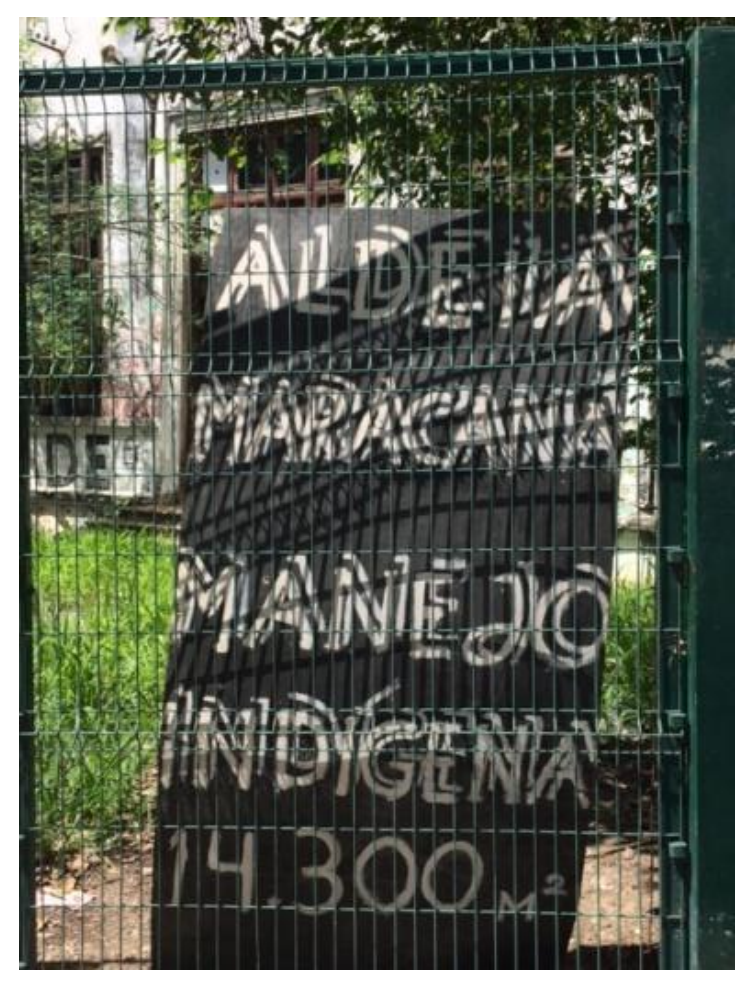

Cartografia onucleo - Aldeia Maracanã - Entrada da Aldeia

$\mathrm{O}$ espaço chama. $\mathrm{O}$ corpo à espreita. 
“Tem gente lá dentro" diz Lídia e meu olho se ajusta à escuridão do lado de dentro da casa e eu vejo, sim, tem gente lá dentro. O chão, o asfalto revirado para levantar do chão a terra: desterrar: revirar a terra:

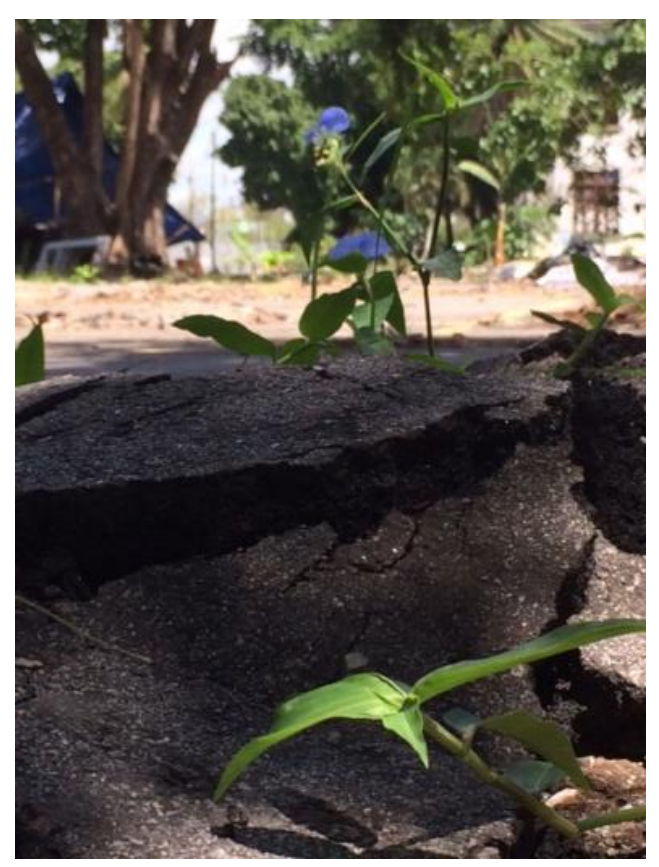

Cartografia onucleo - Aldeia Maracanã - Flor brotando do asfalto 


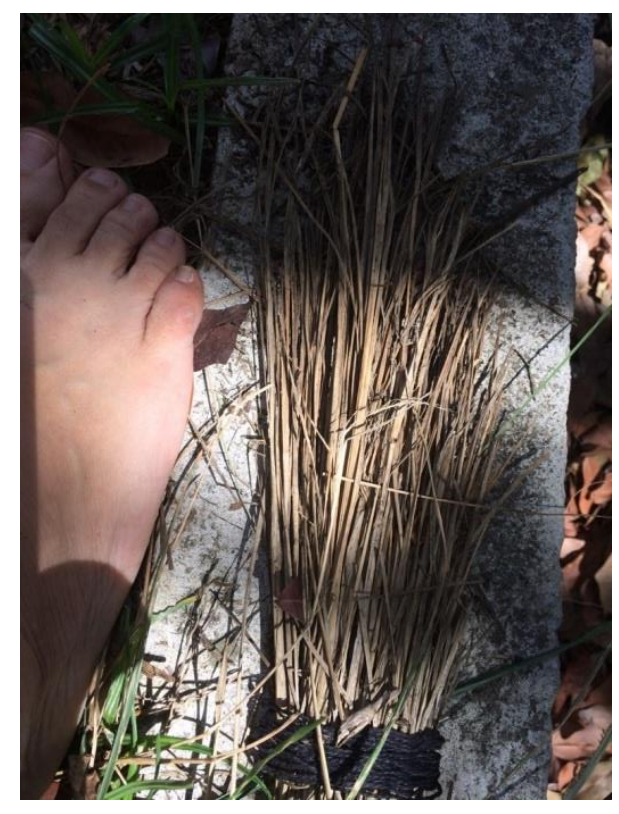

Cartografia onucleo - Aldeia Maracanã - Pé e chão

Devolver terra à Terra. Desterro.

Encontrar a terra do lugar que chama.

Sentamos na beira, no espaço entre a Aldeia e a cidade. Sinto o cheiro da terra, me misturo às suas entranhas que invadem a minha. Lembro a primeira casa que morei, lembro a minha infância misturada à terra...

Vemos adiante duas pessoas que devolvem um olhar tranquilo. Aline levanta como que seguindo um impulso e segue em direção a eles. Depois de algum tempo, Raquel e eu, depois Lídia e Thaís.

Primeiro contato.

A falta de água, a necessidade de receber doações, de que outras pessoas se juntem.

Korubo aparece e somos apresentadas a essa figura mágica que nos encanta com sua presença. Ele nos leva até o casarão, sede da aldeia. 


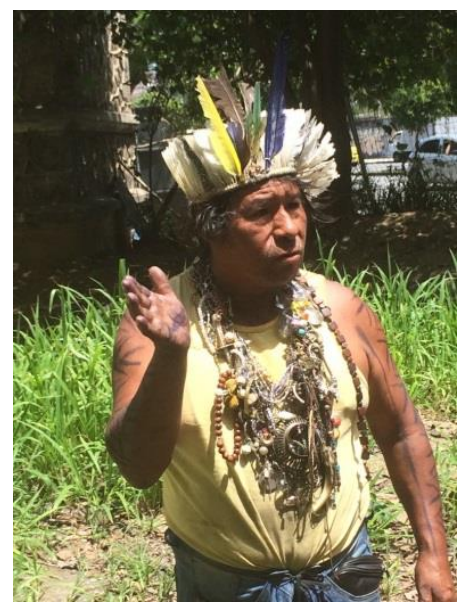

Cartografia onucleo - Aldeia Maracanã - Korubo

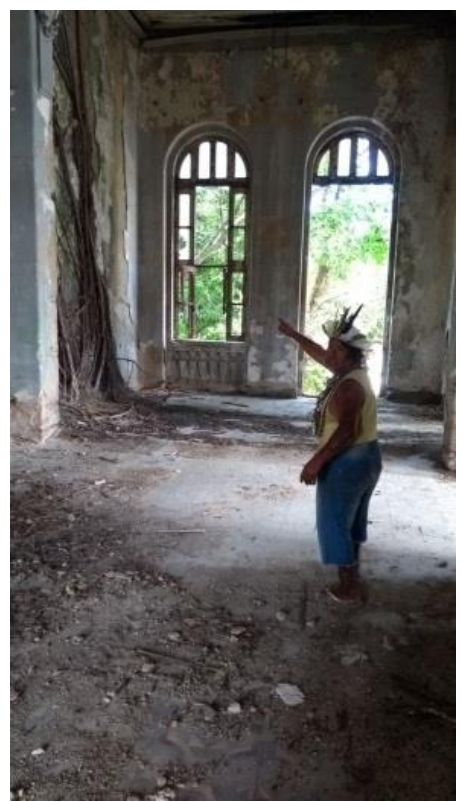

Cartografia onucleo - Aldeia Maracanã - Korubo apresentando a antiga sede do Museu do Índio 


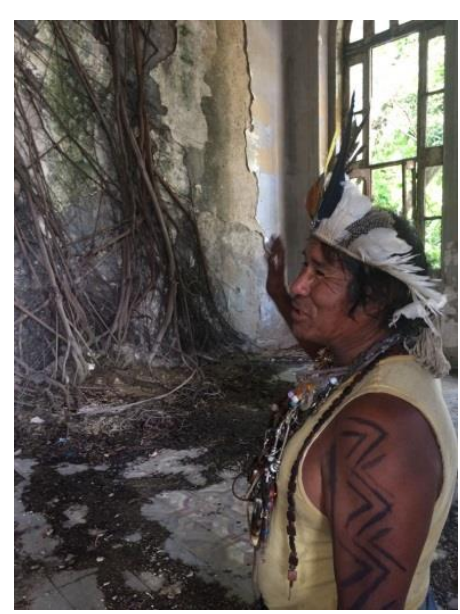

Cartografia onucleo - Aldeia Maracanã - Korubo apresentando a antiga sede do Museu do Índio

Espaço-raiz. Espaço-memória. Espaço-abrigo. Espaço-re-existir.

Lá as árvores crescem pelas paredes, criam raízes por elas, buscando encontrar a terra.

As paredes recebem grafias - desenhos, protestos, sonhos - parecem pele tatuada por muitas histórias, peles-paredes que carregam memória, fendas-feridas de um tempo-templo que resiste.

As janelas se abrem para o céu, para a floresta, para o Morro da Mangueira, para o Maracanã. 


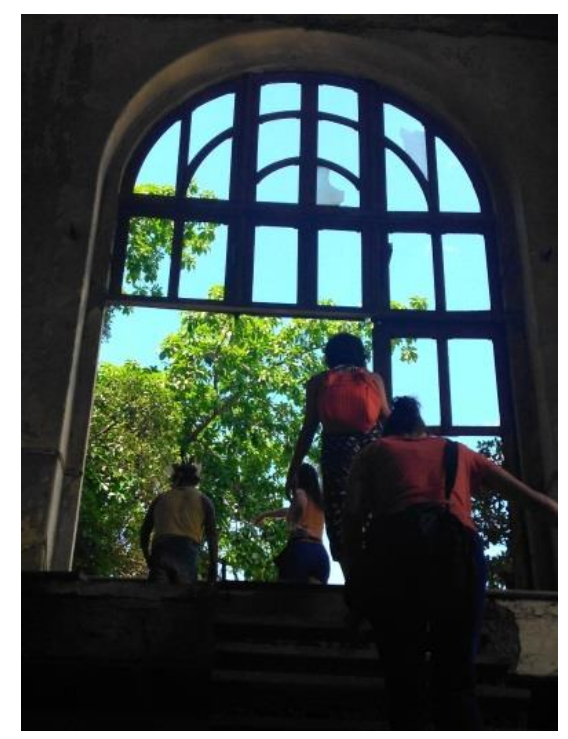

Cartografia onucleo - Aldeia Maracanã - Korubo apresentando a antiga sede do Museu do Índio

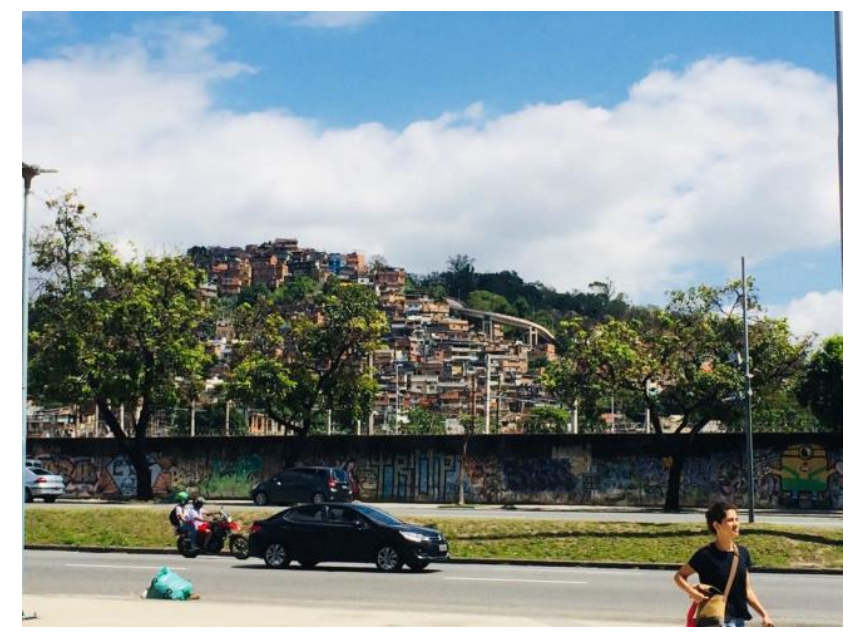

Cartografia onucleo - Aldeia Maracanã - Morro da Mangueira

Espaço-pouso-abrigo-memória-raiz-encanto. Espaço-luto e espaço-luta.

Korubo nos leva pelos cantos daquele espaço e conta histórias. 


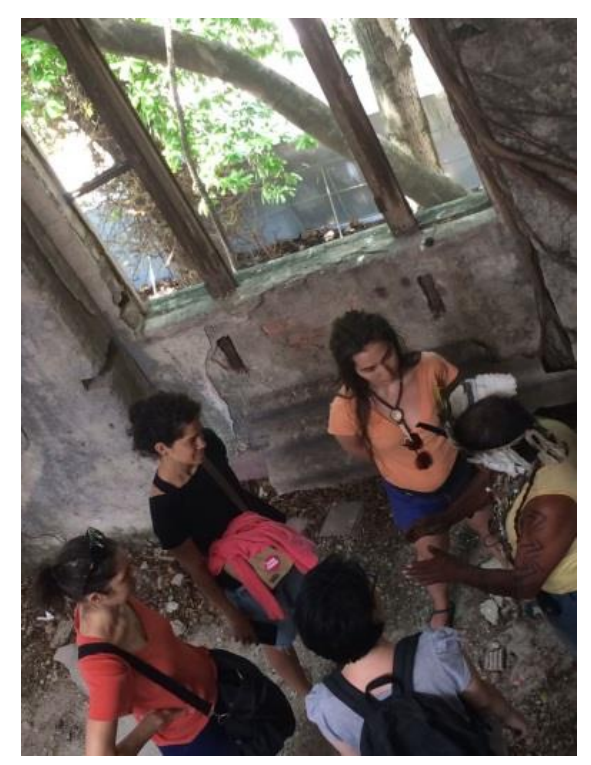

Cartografia onucleo - Aldeia Maracanã - Korubo e seus ensinamentos ancestrais

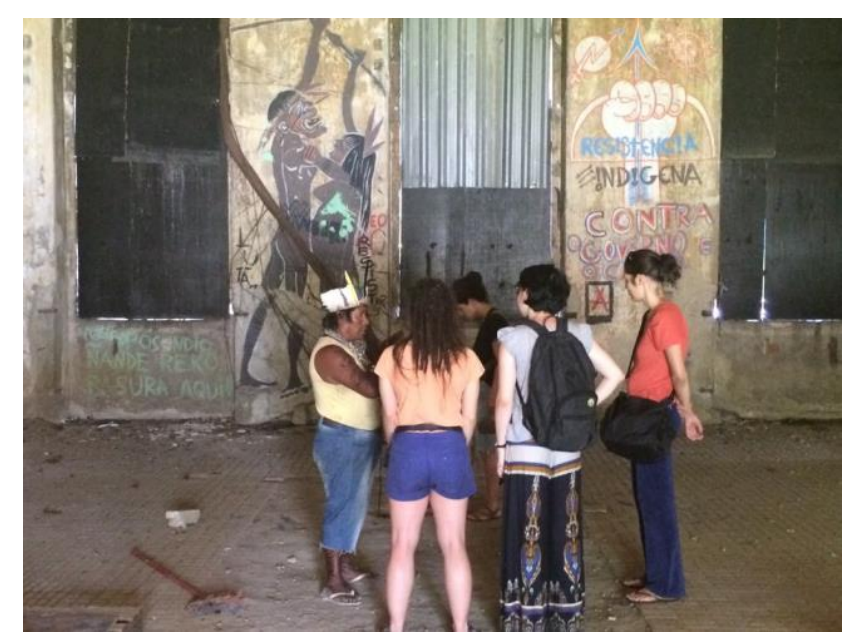

Cartografia onucleo - Aldeia Maracanã - Korubo e seus ensinamentos ancestrais

Incrível sua narrativa que desfaz camadas, mostrando outras: “(...) Vocês são indígenas. Se vocês procurarem saber de onde é sua avó, bisavó, tataravó, você vai saber. Procura na internet, busca saber. (...) Se todo mundo se autodeclarar indígena a terra volta a ser nossa". (...) “O mundo lá fora está corrompido pelo trabalho".(...) “A ciência não vai resolver porque eles não acreditam nos espíritos. Para eles Deus é o dinheiro" Fazer xixi na raiz da árvore, se misturar aos seus elementos. 
Descer as escadas com degraus soltos e ouvir Korubo dizer que para fazer é preciso coragem, com medo não dá para seguir

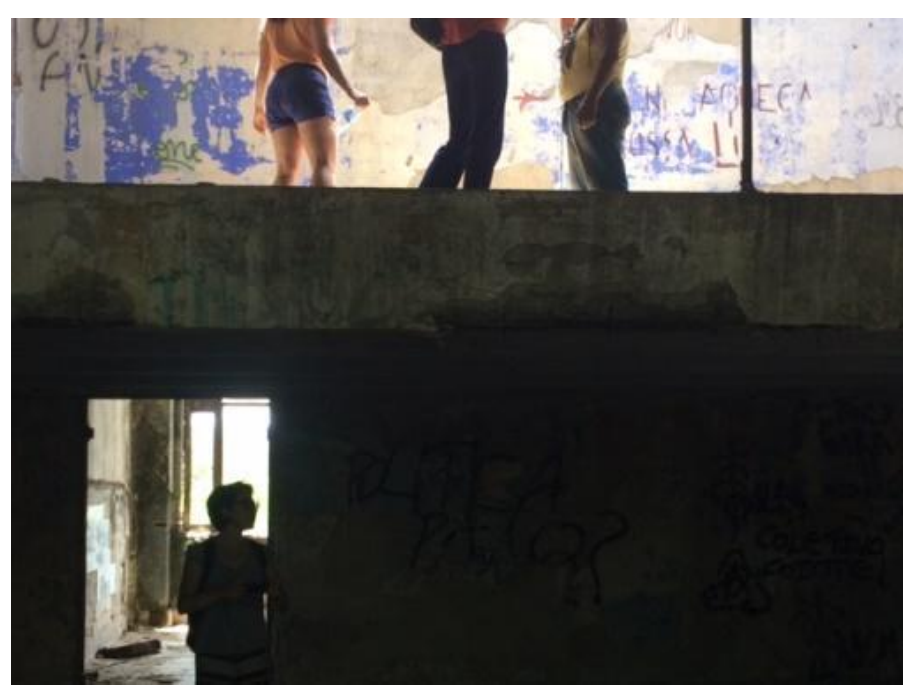

Cartografia onucleo - Aldeia Maracanã - Frestas do espaço

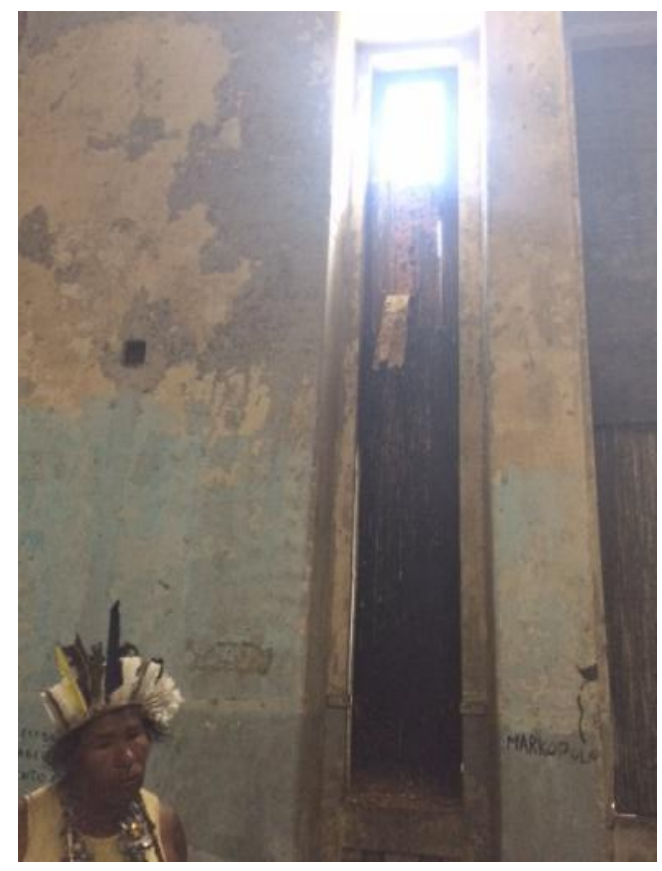

Cartografia onucleo - Aldeia Maracanã - Korubo 
Entrar no canto da meditação e sentir o ar entrar pelas palhas, olhar o céu, sentir todo o corpo se misturar ao espaço. Pousar em si num pouso no espaço. Abrigo para estar e ser outro num tempo outro.

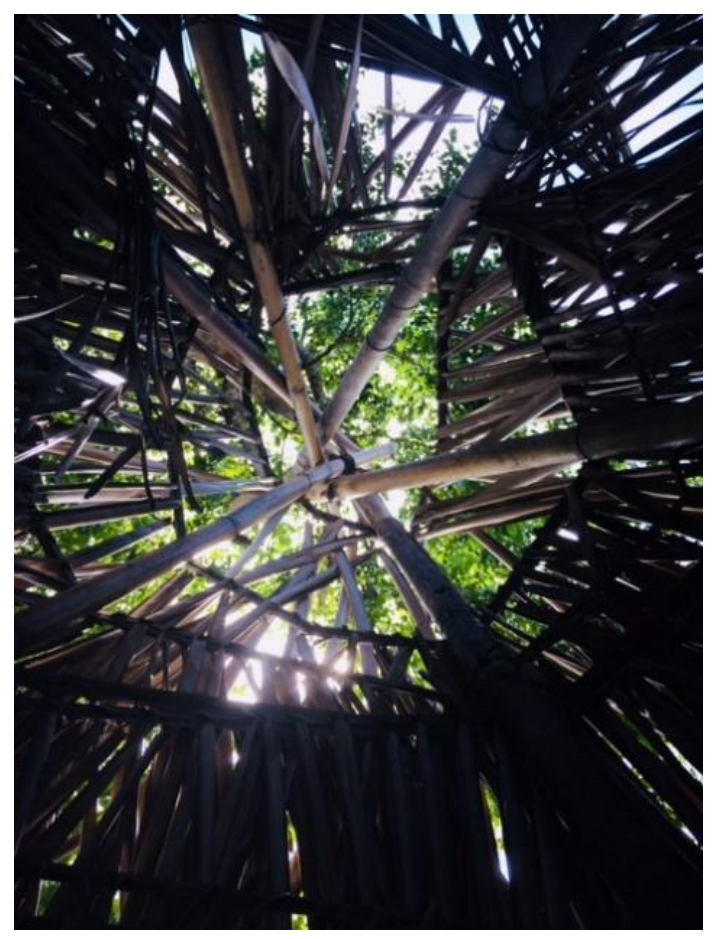

Cartografia onucleo - Aldeia Maracanã - Canto da Meditação 


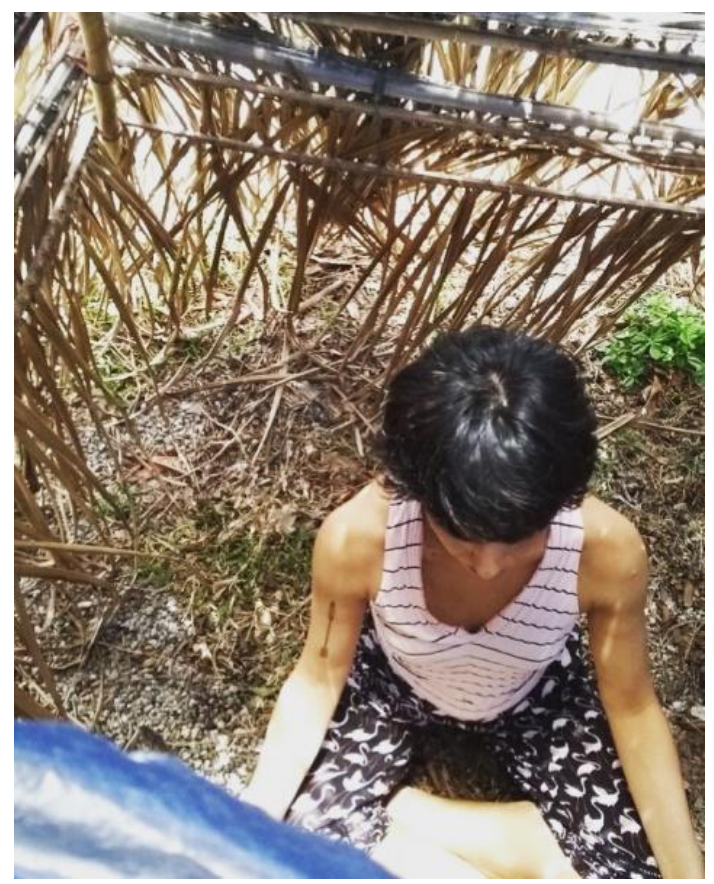

Cartografia onucleo - Aldeia Maracanã - Canto da Meditação

As camadas de tempo remexem as entranhas, estamos reviradas. Difícil dizer depois de tanta vida outra sendo mostrada de modo tão amoroso. Há vida nessas terras que se abrem causando erosão nos dias difíceis de nosso tempo de agora. No intenso agora que se abre para nós brota vida, brota terra fértil e água doce por debaixo do asfalto ${ }^{11}$.

Podemos aqui relacionar o estarcom com essa experiência do teko haw, o lugar onde vivemos, dos povos originários do Brasil. O lugar em que se vive para os povos originários não é diferente do espaço do meu corpo e do espaço do corpo do outro. Por esse motivo, a luta pelo território é também uma luta pelo corpo que se quer ser/estar/ocupar nos espaços políticos, seja na aldeia, seja na cidade. Afinal, é bom lembrar que as fronteiras e as aldeias são construções coloniais impostas a esses povos. Os povos originários estavam mais ocupados na construção de caminhos que permitiam as trocas com o outro, do que na demarcação territorial e não tinham em sua cosmovisão o sentido de privado.

Como nos aponta Sandra Benites (2018), na cultura guarani o corpo é a relação com o outro e é fundamental para a construção do saber. O conhecimento está no bem-viver, no teko 
porã, por isso "para os Guarani, o que está no papel não é tão importante, o que causa um efeito imediato são as práticas do dia a dia” (Benites, 2018: 66)

Estarcom como gesto de cuidado consiste, portanto, numa prática coletiva em que cuidar se configura como estar em presença e em abertura ao território do corpo próprio, do corpo do outro, humano e não humano. Desse modo se configura como uma atitude política e coletiva que consiste na luta pela cidade que se sonha e pelo corpo que se quer ocupar.

Para estarcom é preciso habitar um estado de presença que permita uma abertura ao outro e ao espaço do mundo. O movimento que insurge no estarcom não pertence a um corpo individual. Ele atravessa os corpos, criando a atmosfera do encontro. As corporeidades emergem como efeito da experiência. A pele do encontro permite que os corpos se misturem e se percebam em continuidade entre si e em continuidade com o mundo. Afinamos um diálogo tônico ou um contágio gravitacional (Godard, 2002), nos deixamos ser guiadas pelo encontro, ativando uma escuta das sensações e tecendo uma zona-intensiva-comum entre corpos-espaços. As cartografias em forma de escrita e em forma de imagens são como expressão da experiência do encontro com pessoas e lugares e resultam de uma expansão das corporeidades às presenças e intensidades encontradas.

Um ato de presença pode garantir um tempo de suspensão, um estado de repouso para as intensidades livres poderem passar. Um tempo para fazer pesar, deixar a gravidade atuar, criar densidade ao acontecimento para poder sentir com toda a pele a relação de continuidade corpo-mundo. Deixar a gravidade atuar para possibilitar movimentos grávidos que possam ganhar visibilidade através das cartografias.

Podemos assim afirmar que estarcom é um espaço de partilha. O corpo está presente em sua dimensão territorial compondo mundos com o espaço atmosférico e com os espaços dos outros corpos, humanos e não humanos. Estacom é assim uma expansão do território individual. É um modo de errância com as diferenças dos outros territórios, o que pode nos liberar das ideias e metas individuais e das verdades absolutas da política antropocêntrica. Trata-se de estar presente com a densidade do corpo, com o corpo somático, estar como paisagem, como território, entre a densidade da pele e a densidade do ar, entre os pulmões e a atmosfera da Terra, entre o interior do corpo e o infinito do espaço. Experimentar assim um modo do corpo menos 'ser' e mais 'estar' com o mundo.

\section{Uma flecha para um futuro não tão distante}


\{Convidamos você a sentir a firmeza de suas pernas apoiadas no chão como raízes. Localizar as curvas da coluna como um tronco que te sustente nos espaço. Respirar o hálito do mundo à plenitude dos pulmões. Sentir ou lembrar os efeitos do sol lambendo a pele \}.

São muitas as especulações sobre o mundo que nos espera depois que a pandemia acabar. O que sabemos é que o vírus provocou um levante nos modos de estarcom praticados até aqui. Sonhamos um mundo em que seja possível tocarmos em outras dimensões do estarcom para imaginarmos futuras práticas de cuidado e criação que suponham outras qualidades de presença talvez menos densas, talvez mais oníricas, como nos ensinam os xamãs.

A escrita conjunta desse texto foi uma prática de estarcom como cuidado nesse momento de quarentena. Poder lembrar as práticas realizadas coletivamente pel'onucleo na cidade nos fez sonhar, imaginar um mundo porvir e ativar outros modos de presença. $\mathrm{O}$ estarcom nos ajudou atualizar o corpo deste mundo no nosso corpo de sonho.

Os modos de estarcom que exercitamos na quarentena através da escrita compartilhada, da partilha de sonhos, da escuta sensível, da ativação da memória e de encontros possibilitados pelas tecnologias sofisticou a percepção de sentidos mais telepáticos. Aline Pachamama ${ }^{12}$, em entrevista ao canal "Alô meus nobres" do youtube ${ }^{13}$, nos inspira a imaginar novos modos de telepatia proporcionados pelas mídias virtuais. Pachamama nos convida a sentir-nos em nossas casas, tendo o céu como teto e a Terra como nosso grande chão, dialogando com nossas raízes conectadas, experimentados outros modos de exercício da presença, experimentando o afeto e movendo a esperança na vida.

Exercitar o estarcom, experimentando a partilha, a memória, o afeto e o cuidado, foi um modo de sustentar o céu diante dos desafios de um mundo em queda. Estarcom como um levante para recuperar o vôo quando tudo ao redor cai; como convite a tecer modos de estarcom frente à impossibilidade do encontro; como convocação a sonhar um amanhã para sustentar o céu e adiar o fim. Como finalizar? Como recomeçar?

\section{Referências}


BENITES, Sandra. Viver na língua Guarani: Nhandewa (mulher falando) Dissertação de Mestrado Rio de Janeiro: UFRJ, 2018.

DIAS, Susana Oliveira. WIEDEMANN, Sebastian. e AMORIM, Antônio Carlos Rodrigues. (Org.) Conexões Deleuze e Cosmopoliticas e Ecologias Radicais e Nova Terra e... Campinas, SP: ALB/ClimaCom, 2019.

GODARD, Hubert. Gesto e Percepção. Tradução: Silvia Soter. In: PEREIRA, Roberto;SOTER, Silvia (Org.). Lições de Dança 3. Rio de Janeiro: UniverCidade, 2003. P. 11-35.

KRENAK, Ailton. Ideias para adiar o fim do mundo. São Paulo: Companhia das Letras, 2019.

KOPENAWA, Davi. ALBERT, Bruce. A queda do céu: Palavras de um xamã yanomami. São Paulo: Companhia das Letras, 2015.

LARANGEIRA, Lidia. Coreografias e contracoreografias de levante: engajando dança, escrita e feminilidade. Tese (doutorado) - Universidade do Estado do Rio de Janeiro, Instituto de Artes, 2019.

SACARANO, Fabio Rubio. Regenerantes de Gaia. Rio de Janeiro: Dantes Ed., 2019

WERÁ, Kaká. O Trovão e o Vento: um Caminho de evolução pelo xamanismo tupi-guarani São Paulo: Polar Editora: Instituto Arapoty, 2017.

Lidia Costa Larangeira

Universidade Federal do Rio de Janeiro

Email: 1larangeira@yahoo.com.br

Ruth Silva Torralba Ribeiro

Universidade Federal do Rio de Janeiro

Email: ruthtorralba@gmail.com

\footnotetext{
${ }^{1}$ O COVID-19, ou coronavírus, causa uma doença respiratória aguda com alto poder de contágio e índices de letalidade bastante elevados, principalmente em pessoas acima de 60 anos com comorbidades múltiplas. Configurada como pandemia, a gravidade da doença causou um colapso nos sistemas de saúde de países como Itália e Espanha. O protocolo da Organização Mundial de Saúde recomenda o confinamento e o isolamento social como medida de prevenção e contenção da doença, medida que agudizou a crise na gestão pública brasileira.

2 Nome da peça coreográfica da Lia Rodrigues cia. de danças, de 2016.

${ }^{3}$ DIAS, S. WIEDEMANN, S., e AMORIM, A. (Org.) Conexões Deleuze e Cosmopolíticas e Ecologias Radicais e Nova Terra e... Campinas, SP: ALB/ClimaCom, 2019. p.6.

${ }^{4}$ LARANGEIRA, L. Coreografias e contracoreografias de levante: engajando dança, escrita e feminilidade. Tese (doutorado) - Universidade do Estado do Rio de Janeiro, Instituto de Artes, 2019.

${ }^{5}$ GODARD, H. Gesto e Percepção Tradução de Silvia Soter In Lições de Dança 3 / Roberto Pereira e Silvia Soter (orgs). Rio de Janeiro: UniverCidade. 2003, p. 17).

${ }^{6}$ Ver escrita cartográfica sobre prática de estarcom na Aldeia Maracanã mais adiante, neste texto.

${ }^{7}$ Todas as práticas geraram simultânea ou posteriormente escritas somato-cartográficas e registros audiovisuais que estão disponíveis em: www.onucleo.art
} 
${ }^{8}$ De acordo com Fábio Rubio Sacarano (2019), o termo Antropoceno foi criado por Crutzen e Stoermer em 2000 para caracterizar a atual época geológica caracterizada pelo o grande impacto causado pelo ser humano ao planeta.

${ }^{9}$ Aqui optamos por usar a expressão tupi-guarani, teko haw, do modo como é usada pela Universidade Indígena Pluriétnica e Multicultural Aldeia Maraka’nà.

${ }^{10}$ A Aldeia Maracanã ou Aldeia Maraka'nà, em tupi-guarani, é uma Aldeia Urbana, localizada na antiga sede do Museu do Índio, no bairro do Maracanã. O espaço atualmente é sede da Universidade Indígena Pluriétnica e Multicultural Aldeia Marak'nà. Além de sediar a Universidade Indígena, fortalecendo a transmissão e conhecimento das línguas, das culturas e dos modos de bem-viver dos povos originários, a Aldeia se configura como um espaço de trocas pluriétnicas, proporcionando o encontro de vários povos do Brasil. Além disso, tem sido um importante espaço de resistência da luta indígena na cidade do Rio de Janeiro.

${ }^{11}$ Escrita cartográfica do encontro com a Aldeia Maracanã.

${ }^{12}$ Aline Rochedo Pachamama é indígena do povo Puri, historiadora, Doutora em História Cultural e Mestre em História Social, escritora e ilustradora. Idealizadora da Pachamama Editora. Participa dos Movimentos dos Povos Originários.

${ }^{13}$ https://youtu.be/Lo-GL4 